\title{
Características biométricas de mudas de castanha-do-gurguéia em função de calagem e NPK ${ }^{1}$
}

\author{
Biometric characteristics of Gurguéia nut seedlings as a function of liming and NPK
}

\author{
Raimundo Falcão Neto ${ }^{2 *}$, Gabriel Barbosa da Silva Júnior ${ }^{3}$, Leonardo Fonseca da Rocha ${ }^{3}$, Ítalo Herbert Lucena \\ Cavalcante $^{4}$ e Márkilla Zunete Beckmann-Cavalcante ${ }^{4}$
}

\begin{abstract}
Resumo - A castanha-do-gurguéia (Dipteryx lacunifera Ducke), também conhecida como fava-de-morcego e garampara é uma planta pertencente à família Leguminosae, encontrada na região Meio-Norte do Brasil. A exploração é feita de forma artesanal, demandando, entre outras necessidades, pesquisas relacionadas à nutrição na fase de produção de mudas. Nesse sentido, foi desenvolvido experimento objetivando avaliar as características biométricas na produção de mudas de castanha-do-gurguéia, submetidas a doses de $\mathrm{N}$ e substrato sem e com calcário e PK. As ações foram desenvolvidas no município de Bom JesusPI. Adotou-se delineamento experimental em blocos casualizados com tratamentos distribuídos em esquema fatorial $5 \times 2$ referentes às doses de nitrogênio em cobertura e ao tratamento do substrato, com quatro repetições e três plantas por parcela. As doses de $\mathrm{N}$ testadas foram $0 ; 75 ; 150 ; 225$ e $300 \mathrm{mg} \mathrm{dm}^{-3}$ de solo. As características biométricas avaliadas foram: altura de planta, diâmetro do caule, número de folíolos, massa fresca da parte aérea, massa seca da parte aérea, massa fresca da raiz, massa seca da raiz, volume radicular e comprimento radicular. Houve influência das doses de $\mathrm{N}$ na formação de mudas. $\mathrm{O}$ tratamento do substrato influenciou positivamente o número de folíolos e a massa fresca da parte aérea. Para produção de mudas em substrato não tratado não há necessidade de adubação nitrogenada em cobertura, enquanto para o substrato tratado recomenda-se a dose de $75 \mathrm{mg} \mathrm{dm}^{-3}$.
\end{abstract}

Palavras-chave - Dipteryx lacunifera Ducke. Crescimento vegetal. Qualidade de mudas.

\begin{abstract}
Gurguéia nut (Dipteryx lacunifera Ducke), also known as "fava-de-morcego" and "garampara" is a plant that belongs to leguminosae family, found in the Midle-North region of Brazil. It is explored as handwork, demanding among other requirements, research related to plant nutrition for the seedling production. In this sense an experiment was conducted to evaluate biometric characteristics in the seedling production of Gurguéia nut, submitted to doses of $\mathrm{N}$ and substrate with and without lime and PK. These actions were developed in Bom Jesus County, Piaui State, Brazil. It was used a randomized block experiment with treatments distributed in a factorial arrangement $5 \times 2$, referring to doses of nitrogen and substrate treatment, respectively, with four replications of three plant each one. Nitrogen doses tested were $0 ; 75 ; 150 ; 225$ and $300 \mathrm{mg} \mathrm{dm}^{-3} \mathrm{of}$ soil. The biometric characteristics were evaluated: plant height, stem diameter, number of leaves, shoot fresh mass, fresh root dry mass, root dry mass, root volume and root length. There was influence of nitrogen doses on seedling production. Substrate treatment positively influenced leaf number and shoot fresh dry mass. For seedling production in no treated substrate no nitrogen fertilizing is needed, while for treated substrate it is recommend a $75 \mathrm{mg} \mathrm{dm}^{-3}$ dose.
\end{abstract}

Key words - Dipteryx lacunifera Ducke. Plant growth. Seedling quality.

\footnotetext{
* Autor para correspondência

${ }^{1}$ Recebido para publicação em 15/09/2010; aprovado em 14/05/2011

Parte da dissertação do primeiro autor

${ }^{2}$ Programa de Pós-Graduação em Solos e Nutrição de Plantas, Campus Profa. Cinobelina Elvas (CPCE), Universidade Federal do Piauí, Bom JesusPI, Brasil, falcao@ufpi.br

${ }^{3}$ Bolsista PIBIC/CNPq, CPCE/Universidade Federal do Piauí, Bom Jesus-PI, Brasil, gabrielbarbosa@ufpi.br

${ }^{4} \mathrm{CPCE}$, Universidade Federal do Piauí, Bom Jesus-PI, Brasil, italohlc@ufpi.edu.br
} 


\section{Introdução}

A castanha-do-gurguéia (Dipteryx lacunifera Ducke) é uma planta que se distribui por toda a região Meio-Norte do Brasil, principalmente, nos cerrados do Sul e Centro-sul do Piauí e Maranhão (CARVALHO et al., 2008), explorada com base no extrativismo, que tem suas amêndoas bastante apreciadas pela população e comercializadas em feiras-livres (VIEIRA JUNIOR et al., 2007).

O potencial da castanha-do-gurguéia como frutífera comercial se dá devido ao elevado teor de lipídios $(41,9 \mathrm{~b} \pm 1,29 \%)$ e moderado de proteínas $(14,1 \mathrm{c} \pm 0,06 \%)$ e cinzas $(2,5 \mathrm{~b} \pm 0,20)$ da noz que pode ser usada como ingrediente na produção de barras de cereais (CARVALHO et al., 2008) e na suplementação alimentar de comunidades carentes, além de óleos essenciais contidos nas cascas das frutas poderem ser usadas na indústria farmacêutica (VIEIRA JUNIOR et al., 2007).

Para o desenvolvimento de uma cultura com potencial econômico há necessidade de informações básicas, iniciando pelas recomendações técnicas para produção de mudas de qualidade. A produção de mudas das culturas em geral e, particularmente, das espécies frutíferas tropicais representa um dos mais importantes pré-requisitos para o sucesso do empreendimento agrícola. Portanto, alguns critérios devem ser adotados como, aquisição de material biológico de boa qualidade, uso de sementes fitossanitariamente sadias, substratos com composição e volumes adequados, manejo de adubação e balanço nutricional (HARTMANN et al., 2002).

Os parâmetros utilizados para determinar a qualidade da muda baseiam-se em aspectos morfológicos e fisiológicos, como: altura da parte aérea, desenvolvimento do sistema radicular, diâmetro do colo, produção de massa seca e verde das partes aérea e radicular, e aspectos nutricionais (HARTMANN et al., 2002). Os aspectos morfológicos são os mais utilizados para determinar o padrão de qualidade das mudas (GOMES et al., 2002), destacando-se que esse aspecto tem uma compreensão mais intuitiva e necessita de uma definição mais precisa para atender às exigências quanto à sobrevivência e ao crescimento, determinadas pelas adversidades encontradas no campo após o plantio.

Nesse sentido, a definição de doses adequadas de nutrientes, principalmente o nitrogênio, bem como a necessidade de preparo do substrato constitui em avanço na produção de mudas dessa potencial espécie, como já foi estudado para outras espécies nativas. Benedetti et al. (2009), trabalhando com espinheira-santa (Maytenus ilicifolia), em solução nutritiva na omissão de nitrogênio, observaram que as plantas demonstraram desenvolvimento abaixo do normal, com clorose generalizada. Cruz et al. (2006) em trabalho com a produção de mudas de sete-cascas (Samanea inopinata (Harms) Ducke), uma planta pertencente à família Leguminosae Mimosoideae, concluíram que a adubação nitrogenada com sulfato de amônio afetou significativamente todos os parâmetros morfológicos avaliados (altura, diâmetro do coleto e matéria seca da parte aérea e da raiz). Adicionalmente, Marques et al. (2006a), em estudo com a produção de mudas de sabiá (Mimosa caesalpiniaefolia Benth) planta da família Leguminosae, verificaram que a altura de planta foi significativamente influenciada pelas doses de N.

Objetivou-se com o presente experimento avaliar as características biométricas na produção de mudas de castanha-do-gurguéia, submetidas às doses de $\mathrm{N}$ em substrato sem e com calcário e PK.

\section{Material e métodos}

O experimento foi desenvolvido no município

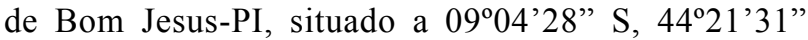
O e altitude média de $277 \mathrm{~m}$, durante o período de 02/12/2010 a 13/03/2010. O experimento foi realizado no setor de horticultura sob ambiente protegido a $50 \%$ de luminosidade.

Durante a execução do experimento foram monitoradas diariamente a temperatura média e umidade relativa do ar (thermo-higromêtro digital, Quimis $^{\circledR}$ ) às 15:00 horas e a intensidade luminosa (luxímetro digital, Instrutherm ${ }^{\circledR}$ ) às 12:00 horas no interior da estufa, cujas representações de dispersão encontram-se na Figura 1.

Como substrato foi usado um NEOSSOLO QUARTZARÊNICO coletado na camada de 20 a 40 $\mathrm{cm}$ de profundidade e peneirado, cujas características químicas antes e após a calagem encontram-se na Tabela 1.

As sementes para a produção das mudas foram adquiridas de frutos oriundos de plantas nativas do município de Bom Jesus-PI conduzidas sem manejo específico quanto à adubação, poda, irrigação e controle fitossanitário. Após a colheita, os frutos foram conduzidos ao laboratório para seleção e uniformização, onde foi promovida a extração manual da polpa e as sementes foram imersas em água durante 24 horas, objetivando superação de dormência, conforme recomendações de Rocha (2009). Em seguida as sementes foram envolvidas em papel filtro e umedecidas diariamente. Após germinação, as plântulas foram padronizadas quanto ao número de folhas e repicadas às sacolas plásticas em 11/01/2010. 

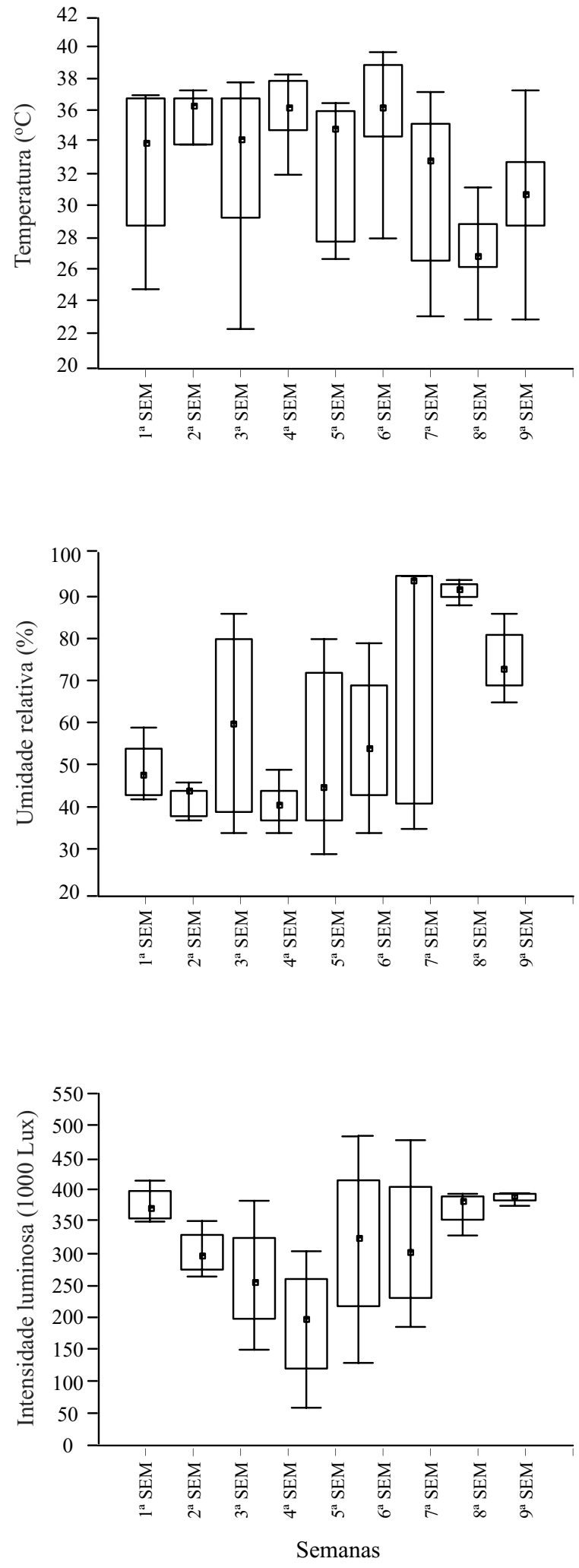

Legenda: $\square$ Mediana $\square$ 25\%-75\% dos dados $\square$ Amplitude

Figura 1 - Diagrama de dispersão da temperatura média, umidade relativa do ar e intensidade luminosa no interior da estufa em função das semanas de execução do experimento
Tabela 1 - Caracterização química do solo usado no experimento antes e após a calagem

\begin{tabular}{lcc}
\hline \multirow{2}{*}{ Variável } & Antes da calagem & Após a calagem \\
\cline { 2 - 3 } & $----------\left(\mathrm{cmol}_{\mathrm{c}} \mathrm{dm}^{-3}\right)$----------- \\
\hline $\mathrm{pH}$ & 5,33 & 6,80 \\
$\left(\mathrm{Ca}^{2+}+\mathrm{Mg}^{2+}\right)$ & 0,56 & 6,40 \\
$\mathrm{Ca}^{2+}$ & 0,32 & 4,38 \\
$\mathrm{~K}^{+}$ & 0,01 & 4,00 \\
$\mathrm{Na}^{+}$ & 0,01 & 0,00 \\
$\mathrm{Al}^{3+}$ & 0,36 & 0,00 \\
$\left(\mathrm{H}^{+}+\mathrm{Al}^{3+}\right)$ & 1,10 & 0,80 \\
M.O. $\left(\mathrm{g} \mathrm{kg}^{-1}\right)$ & 2,33 & - \\
\hline
\end{tabular}

M.O.= matéria orgânica

Como recipientes foram usadas sacolas plásticas nas dimensões $16 \times 26 \mathrm{~cm}$, preenchidas com substrato e padronizados em massa equivalente a $2,7 \mathrm{~kg}$. Para determinação da necessidade de reposição hídrica diária, as sacolas foram preenchidas com substrato e saturadas até a capacidade de campo e novamente pesadas registrando-se como massa de referência $2,982 \mathrm{~kg}$. Diariamente as sacolas foram pesadas (balança digital Balmak Economic ${ }^{\circledR}$ ) e o quantitativo equivalente a $70 \%$ da evaporação foi reposta.

Adotou-se delineamento experimental em blocos casualizados com os tratamentos distribuídos em esquema fatorial $5 \times 2 \mathrm{com} 4$ repetições. O primeiro fator correspondeu às doses de nitrogênio em cobertura e o segundo ao substrato tratado. As doses de $\mathrm{N}$ testadas foram $0 ; 75 ; 150 ; 225$ e $300 \mathrm{mg} \mathrm{dm}{ }^{-3}$, considerando-se como padrão a dose de $300 \mathrm{mg} \mathrm{dm}^{-3} \mathrm{de} \mathrm{N}$, indicada como adequada por Malavolta (1980) para experimentos em condições de vasos. $\mathrm{O}$ substrato tratado correspondeu às práticas de calagem e adubação com fósforo e potássio.

No substrato tratado fez-se a aplicação de calcário $(\mathrm{CaO}=32 \% ; \mathrm{MgO}=11 \% ; \mathrm{S}=4 \% ; \mathrm{PN}=$ $70 \%$; PRNT $=60 \%$ ), empregando-se o método do $\mathrm{Al}$ trocável, o que corresponde à dose de $3,0 \mathrm{t} \mathrm{ha}^{-1} \mathrm{ou}$ $4,05 \mathrm{~g}$ por sacola de $2,7 \mathrm{dm}^{-3}$ e mantida a incubação por 30 dias para posterior semeadura. Além da calagem o substrato tratado recebeu ainda $1,11 \mathrm{~g}$ de fósforo/muda ou $411 \mathrm{mg} \mathrm{dm}^{-3}$ de fósforo (fonte: superfosfato simples, $18 \%$ de $\mathrm{P}_{2} \mathrm{O}_{5}$ ) misturado ao substrato antes do enchimento das sacolas e $150 \mathrm{mg} \mathrm{dm}^{-3}$ de potássio (fonte: cloreto de potássio, $60 \%$ de $\mathrm{K}_{2} \mathrm{O}$ ), parcelado da seguinte forma: $30 \mathrm{mg} \mathrm{dm}^{-3}$ aos sete dias após a repicagem; $45 \mathrm{mg} \mathrm{dm}^{-3}$ aos 21 e 35 dias após a repicagem e $30 \mathrm{mg} \mathrm{dm}^{-3}$ aos 
49 dias após a repicagem. Já o $\mathrm{N}$ na forma de uréia (45\% de N) foi utilizado em três aplicações (aos 7; 22 e 37 dias após a repicagem das mudas), nos respectivos percentuais: primeira e segunda aplicação $40 \%$ de cada dose recomendada e terceira aplicação $20 \%$ de cada dose recomendada, via água de irrigação. As adubações seguiram as recomendações de Malavolta (1980).

Aos 60 dias após a repicagem, foram avaliadas: i) altura de planta: determinada da superfície do solo à inserção da última folha com auxílio de régua milimetrada; ii) diâmetro do caule: mensurado a $2 \mathrm{~cm}$ da superfície do solo por meio de leituras em paquímetro digital (Digimess ${ }^{\circledR}$ ); e iii) número de folíolos: contagem visual. Em seguida as plantas foram separadas em parte aérea e sistema radicular para determinação de: i) massa fresca (g) e seca (mg) de raiz e de parte aérea: determinados por pesagem (balança Bioprecisa ${ }^{\circledR}$ ); ii) comprimento da maior raiz $(\mathrm{cm})$ : realizado com régua milimetrada; iii) volume radicular $\left(\mathrm{cm}^{3}\right)$ : realizada por meio da medição do deslocamento da coluna de água em proveta graduada, ou seja, colocando-se as raízes, após lavagem, em proveta contendo um volume conhecido de água $(100 \mathrm{~mL})$. Pela diferença, obteve-se a resposta direta do volume de raízes, pela equivalência de unidades $\left(1 \mathrm{~mL}=1 \mathrm{~cm}^{3}\right)$, segundo metodologia descrita por Basso (1999). Para mensuração das massas secas, o material vegetal foi conduzido à estufa com circulação forçada de ar à temperatura de $65^{\circ} \mathrm{C}$ até atingir peso constante.

Os dados foram submetidos à análise de variância, pelo teste "F", para diagnóstico de efeito significativo (1 e 5\% de significância), as médias do fator substrato tratado foram comparadas entre si pelo teste de Tukey (1\% de significância) utilizando o software Assistat e os níveis de $\mathrm{N}$ foram submetidos à análise quantitativa de regressão polinomial (teste $\mathrm{F}$ a $1 \%$ de significância) no software Sigmaplot. Foi realizada ainda análise de correlação entre todas as variáveis dependentes do estudo no software Statistica 5.0.

\section{Resultados e discussão}

Pelos resultados da análise de variância contidos na Tabela 2, observam-se diferenças significativas para a aplicação de calcário e PK no substrato apenas para número de folíolos e massa fresca da parte aérea, já com relação às doses de nitrogênio todas as variáveis estudadas (altura de planta, diâmetro do caule, número de folíolos, massa fresca e massa seca da parte aérea) apresentaram diferenças significativas.

As plantas que receberam a dose de $300 \mathrm{mg} \mathrm{dm}^{-3}$ de $\mathrm{N}$ apresentaram mortalidade de quase $100 \%$, inclusive com sintomas visuais de toxidez pela aplicação excessiva desse nutriente.

A interação entre o tratamento do substrato e as doses de nitrogênio exerceu efeitos significativos para altura de planta, número de folíolos, massa fresca e massa seca da parte aérea (TAB. 2), situação que evidencia interdependência entre os fatores estudados para estas variáveis, entretanto somente a variável diâmetro do caule apresentou interação não significativa.

Com relação às variáveis, número de folíolos e massa fresca da parte aérea houve diferença estatística, onde as plantas cultivadas no substrato tratado apresentaram aumento percentual de 11,14 e 12,14\%

Tabela 2 - Altura de planta (AP), diâmetro do caule (DC), número de folíolos (NF), massa fresca da parte aérea (MFPA) e massa seca da parte aérea (MSPA) de mudas de castanha-do-gurguéia em função de doses de $\mathrm{N}$ e da aplicação de calcário e PK no substrato

\begin{tabular}{|c|c|c|c|c|c|}
\hline \multirow{2}{*}{ Fonte de variação } & $\mathrm{AP}$ & $\mathrm{NF}$ & MFPA & MSPA & $\mathrm{DC}$ \\
\hline & ---- $(\mathrm{cm})--\cdot--$ & & ----- (g) ----- & -------(mg)------- & ------(mm)------ \\
\hline S (Trat. do solo) & $0,06^{\mathrm{ns}}$ & $6,50 *$ & $5,95 *$ & $0,72^{\text {ns }}$ & $0,04^{\mathrm{ns}}$ \\
\hline $\mathrm{S} 1$ & $7,24 \mathrm{a}$ & $35,73 \mathrm{a}$ & $1,89 \mathrm{a}$ & $0,81 \mathrm{a}$ & $2,67 \mathrm{a}$ \\
\hline $\mathrm{S} 2$ & $7,16 \mathrm{a}$ & $31,75 \mathrm{~b}$ & $1,66 \mathrm{~b}$ & $0,77 \mathrm{a}$ & $2,65 \mathrm{a}$ \\
\hline DMS & 0,67 & 2,25 & 0,19 & 0,09 & 0,14 \\
\hline $\mathrm{N}($ doses de $\mathrm{N})$ & $38,44 * *$ & $58,05 * *$ & $51,97 * *$ & $38,48 * *$ & $20,59 * *$ \\
\hline $\mathrm{S} \times \mathrm{N}$ & $4,38 *$ & $8,81 * *$ & $8,15^{* *}$ & $6,52 * *$ & $2,26^{\mathrm{ns}}$ \\
\hline$\overline{C V}$ & 2,72 & 13,08 & 14,99 & 15,28 & 7,08 \\
\hline
\end{tabular}

DMS = diferença mínima significativa; $\mathrm{CV}=$ coeficiente de variação; $\mathrm{S} 1=$ substrato tratado; $\mathrm{S} 2=$ substrato não tratado; ${ }^{\text {NS }}=$ não significativo; ${ }^{*}=$ significativo ao nível de $5 \% ;{ }^{* *}=$ significativo ao nível de $1 \%$; as médias seguidas pela mesma letra em cada coluna, não são diferentes estatisticamente pelo teste de Tukey a $5 \%$ 
maior em relação ao não tratado, respectivamente (TAB. 2).

Em função das doses de $\mathrm{N}$, as plantas do substrato não tratado que não receberam adubação de cobertura $\left(0 \mathrm{mg} \mathrm{dm}^{-3} \mathrm{de} \mathrm{N}\right)$ obtiveram um incremento de $53,03 \%$ (FIG. 2B) maior em altura que as plantas que receberam $225 \mathrm{mg} \mathrm{dm}^{-3}$ de $\mathrm{N}$, já as plantas do substrato tratado obtiveram apenas incremento de $37,25 \%$ para a mesma variável nas mesmas condições (FIG. 2A).

Marques et al. (2006a), trabalhando com produção de mudas de sabiá (Mimosa caesalpiniaefolia Benth) planta da família Leguminosae, verificou que a altura de planta foi significativamente influenciada pelas doses de $\mathrm{N}$, aumentando linearmente com o acréscimo das doses, resultado divergente ao encontrado no presente estudo. Por outro lado Santin et al. (2008) trabalhando com erva-mate, concluíram que a adubação nitrogenada promoveu efeitos negativos para altura de planta, diâmetro do colo, massa fresca da parte aérea, massa seca da parte aérea e massa seca da raiz, portanto em concordância com os resultados da Figura 2.

Chaves et al. (2003) avaliando adubação nitrogenada na produção de mudas de sesbânia (Sesbania virgata), pertencente à família Leguminosae, constataram que a aplicação de diferentes doses de nitrogênio, não alterou o crescimento em altura e diâmetro das mudas.

Os resultados encontrados demonstram a necessidade de estudos específicos para espécies leguminosas, dentre as quais a castanha-do-gurguéia, principalmente porque há poucos estudos sobre a fixação biológica do $\mathrm{N}$ nessa espécie, bem como não se identifica uma recomendação de inoculantes estimulantes da fixação de N.

Observa-se no presente trabalho que houve correlação negativa $\left(\mathrm{R}=-0,72^{* *}\right)$ entre a massa seca de parte aérea e a altura de planta e, paralelamente, correlação positiva entre o número de folíolos e massa seca da parte aérea $\left(\mathrm{R}=0,81^{* *}\right)$, resultados que evidenciam o direcionamento do desenvolvimento vegetal da castanha-do-gurguéia em detrimento do crescimento em altura durante a fase de formação da muda.

Pelos dados contidos na Figura 3A percebe-se que as mudas que mais desenvolveram folíolos no substrato com calcário e PK foram aquelas que receberam em cobertura a dose de $75 \mathrm{mg} \mathrm{dm}^{-3}$ de N. Já no substrato não tratado (FIG. 3B) observa-se incremento percentual de $53,45 \%$ em numero de folíolos das mudas da testemunha sobre aquelas que receberam a dose $225 \mathrm{mg} \mathrm{dm}^{-3} \mathrm{de} \mathrm{N}$. A massa fresca da parte aérea (FIG. 4A) das mudas produzidas no substrato tratado que receberam $75 \mathrm{mg}$ $\mathrm{dm}^{-3}$ apresentou um acréscimo de $17,39 \%$ com relação à aquelas que não receberam adubação em cobertura, por outro lado, no substrato não tratado (FIG. 4B) houve um decréscimo dessa variável de $30,47 \%$ das mudas produzidas sem adubação de cobertura sobre aquelas que receberam $75 \mathrm{mg} \mathrm{dm}^{-3}$, resultado em parte semelhante à massa seca da parte aérea com e sem tratamento de substrato (FIG. 5).
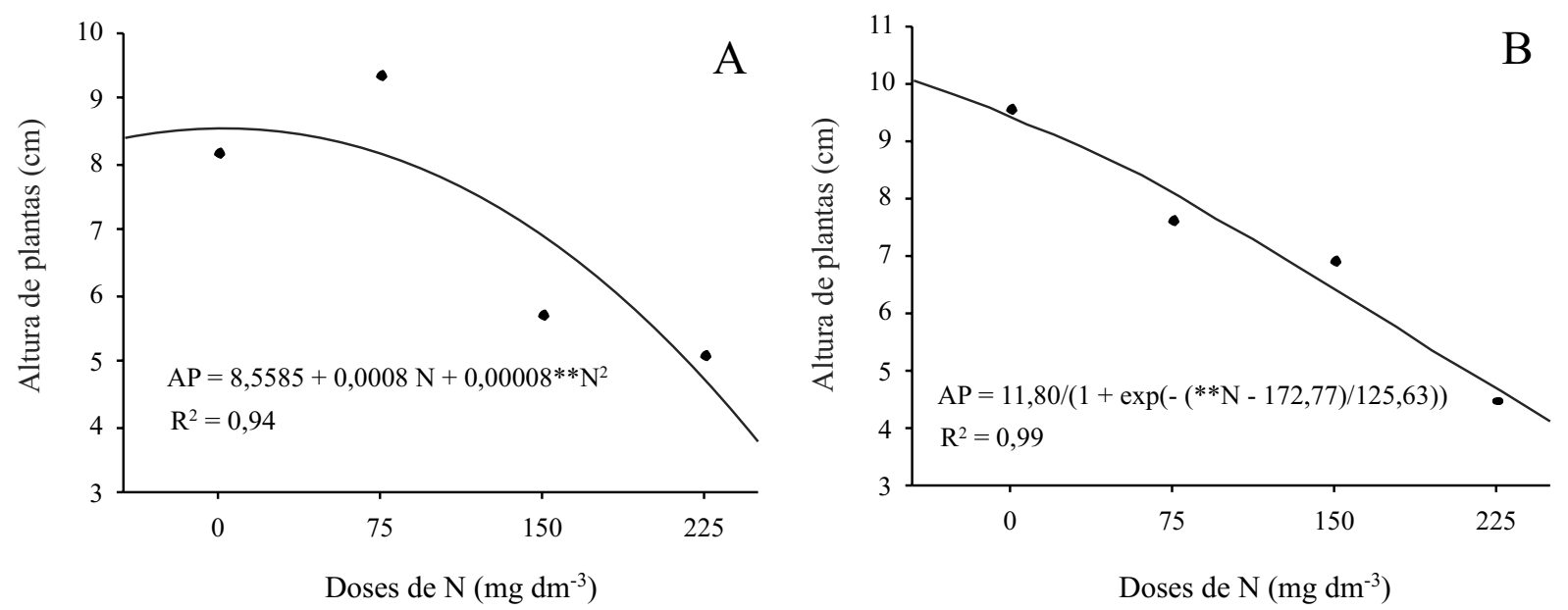

Figura 2 - Altura de planta (AP) de mudas de castanha-do-gurguéia em substrato com (A) e sem calcário e PK (B) e em função de doses de $\mathrm{N}$ 

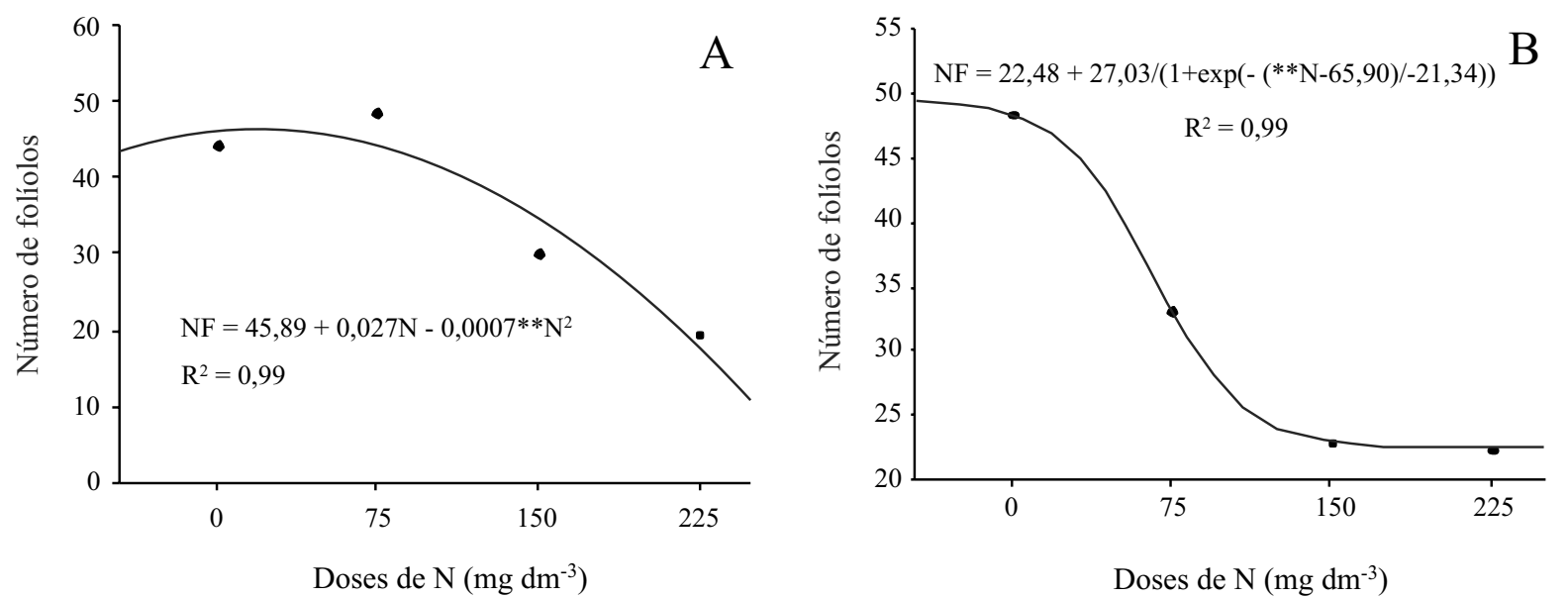

Figura 3 - Número de folíolos (NF) de mudas de castanha-do-gurguéia em substrato com (A) e sem calcário e PK (B) e em função de doses de $\mathrm{N}$
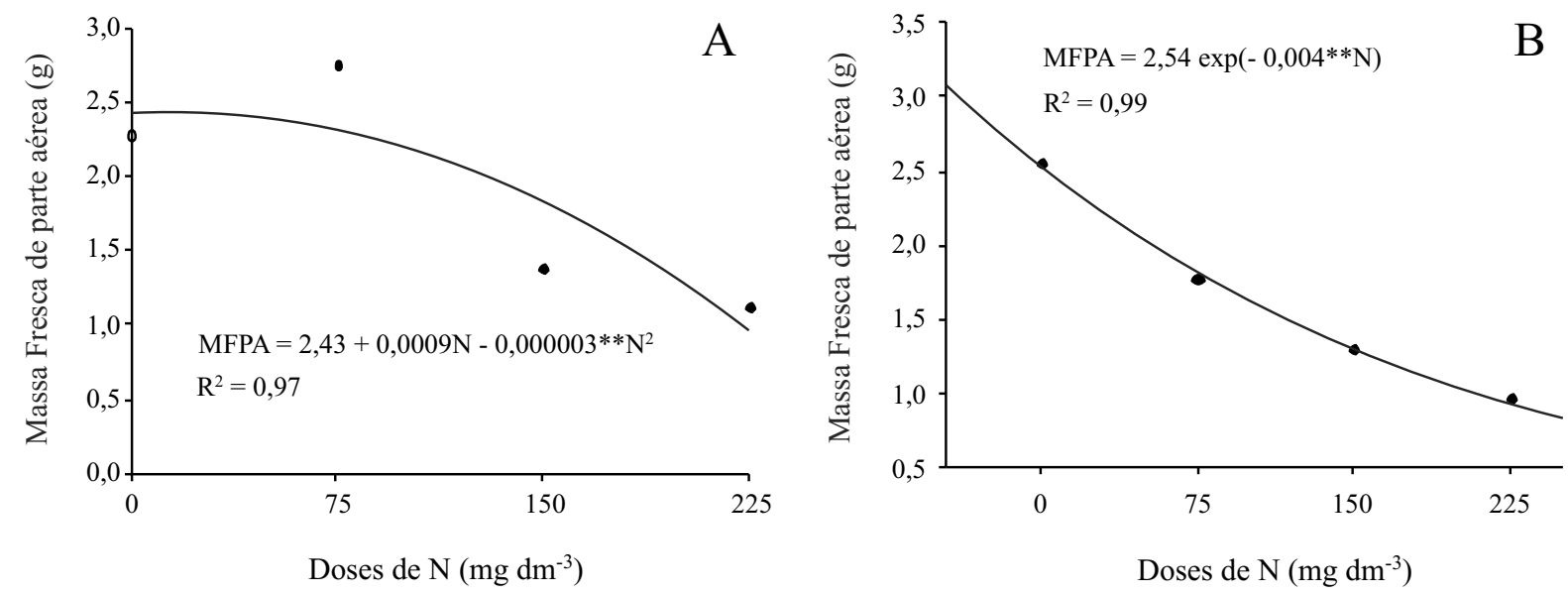

Figura 4 - Massa fresca de parte aérea (MFPA) de mudas de castanha-do-gurguéia em substrato com (A) e sem calcário e PK (B) e em função de doses de $\mathrm{N}$

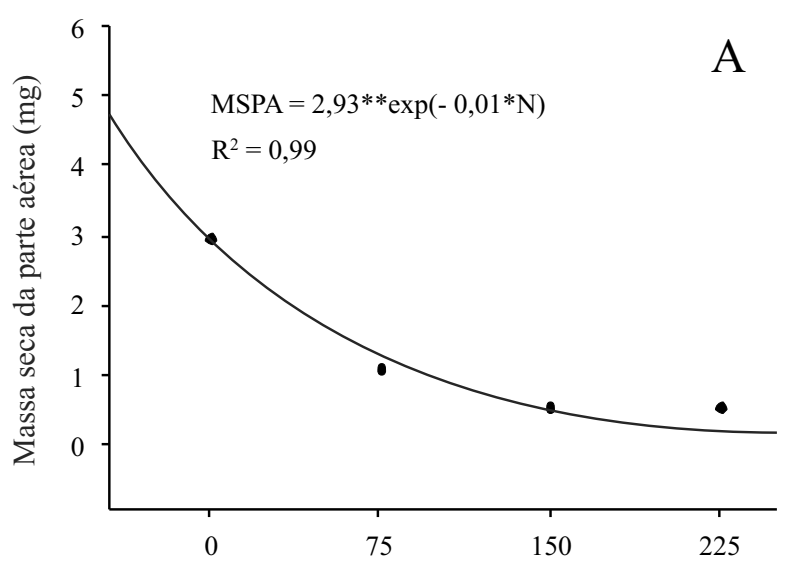

Doses de $\mathrm{N}\left(\mathrm{mg} \mathrm{dm}^{-3}\right)$

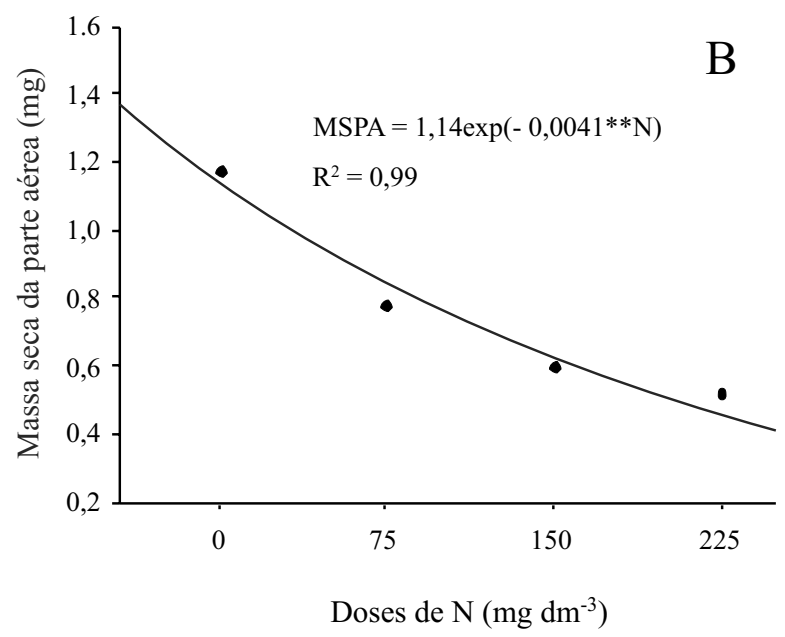

Doses de $\mathrm{N}\left(\mathrm{mg} \mathrm{dm}^{-3}\right)$

Figura 5 - Massa seca de parte aérea (MSPA) de mudas de castanha-do-gurguéia em substrato com (A) e sem calcário e PK (B) e em função de doses de $\mathrm{N}$ 
Para diâmetro do caule (FIG. 6) ocorreu decréscimo exponencial nessas médias com o aumento das doses de $\mathrm{N}$, resultado semelhante ao encontrado por Santin et al. (2008), trabalhando com produção de mudas de erva-mate.

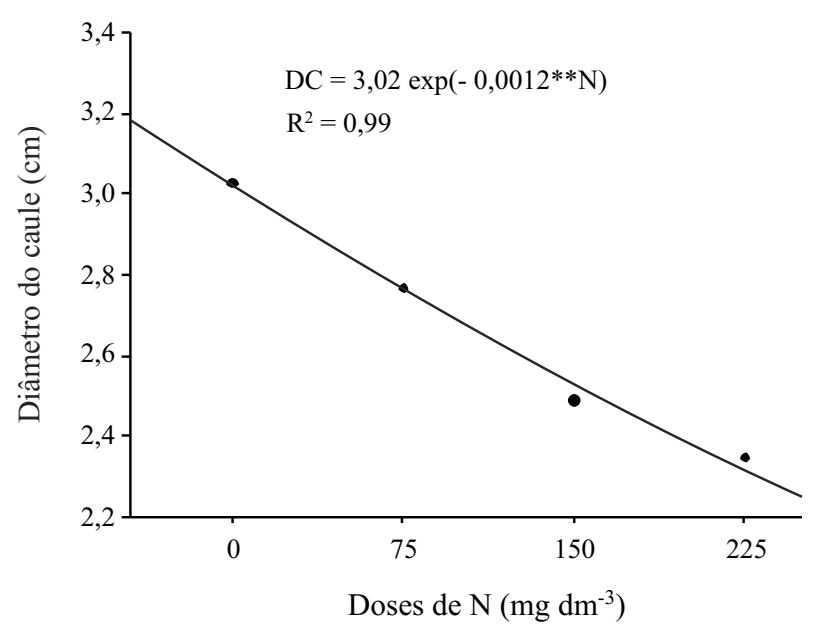

Figura 6 - Diâmetro do caule (DC) de mudas de castanha-dogurguéia em função de doses de $\mathrm{N}$

Numa avaliação global das variáveis de parte aérea observa-se que as duas menores doses de $\mathrm{N}$ (0 e $\left.75 \mathrm{mg} \mathrm{dm}^{-3}\right)$, invariavelmente, apresentaram as maiores médias, independentemente do tratamento do solo. Quanto a esse resultado é possível inferir que possivelmente o teor de matéria orgânica inicial do solo usado como substrato $\left(2,33 \mathrm{~g} \mathrm{~kg}^{-1}\right)$ pode ter sido suficiente para suprir a planta de castanha-do-gurguéia durante a fase de formação de mudas ou a fixação biológica no nitrogênio possa ter sido satisfatória, visto que não foram identificados sintomas visuais de deficiência em quaisquer das doses de $\mathrm{N}$, inclusive na testemunha. Ressalta-se que não são conhecidos ainda na literatura científica os requerimentos dessa espécie na fase inicial de desenvolvimento.

Fernandes et al. (2008) trabalhando com fava d'anta (Dimorphandra mollis Benth), planta da família Leguminosae, em LATOSSOLO VERMELHOAMARELO com $24 \mathrm{~g} \mathrm{~kg}^{-1}$ ou seja $2,4 \%$ de matéria orgânica observaram que as máximas produções de massa seca da parte aérea e massa seca da raiz foram obtidas nas doses de 237 e $245 \mathrm{mg} \mathrm{dm}^{-3}$, respectivamente, enquanto para altura de planta e diâmetro do caule os maiores valores foram encontrados nas doses de 226 e $200 \mathrm{mg} \mathrm{dm}^{-3}$, respectivamente. Embora a adubação nitrogenada possa inibir a nodulação conforme verificaram Araújo et al. (2007), no presente estudo foi verificada a presença de nódulos nas raízes mesmo nos níveis mais elevados de $\mathrm{N}$. Resultados semelhantes foram encontrados por Marques et al. (2006b) em experimento com produção de mudas de jacarandá-dabahia (Dalbergia nigra (Vell.) Fr.All. ex Benth.) planta também da família Leguminosae, onde se verificou que a altura de planta foi significativamente influenciada pelas doses de $\mathrm{N}$, aumentando linearmente, com o acréscimo das doses independente da fonte.

De uma forma geral os principais aspectos de excesso de nitrogênio absorvido e metabolizado estão relacionados ao desvio de carboidratos para as proteínas, que promove excesso de desenvolvimento vegetativo da parte aérea, em detrimento do reprodutivo, causando também aumento da relação parte aérea/raiz, prejudicando o desenvolvimento do sistema radicular e capacidade de resistência das plantas a períodos secos bem como o acamamento das mesmas, podendo levar a morte da planta (PRADO, 2008).

As formas preferenciais de absorção de $\mathrm{N}$ pelas plantas são a amoniacal $\left(\mathrm{NH}_{4}^{+}\right)$e a nítrica $\left(\mathrm{NO}_{3}^{-}\right)$, destacando-se que as plantas, de modo geral, respondem bem a adubação nitrogenada, porém, o excesso de $\mathrm{N}$ é prejudicial (MARSCHNER, 2005). De acordo com Prado (2008), o N absorvido na forma nítrica pode ser armazenado no vacúolo das células ou metabolizado, no entanto o $\mathrm{N}$ absorvido na forma amoniacal deve ser todo metabolizado, pois ao se acumular na planta pode ser tóxico, podendo causar a morte da mesma, o que aconteceu com todas as plantas que receberam a dose de $300 \mathrm{mg} \mathrm{dm}^{-3}$ de N. Adicionalmente, há possibilidade de excesso de uréia na planta causado por um possível teor baixo de níquel, visto que esse elemento participa na estrutura e no funcionamento da enzima uréase, responsável pela quebra da uréia na planta (GERENDAS et al., 1999).

Pelos resultados da análise de variância contidos na Tabela 3, não se observam diferenças significativas para o tratamento do substrato, para massa fresca e massa seca da raiz, volume radicular e comprimento radicular. Entretanto, a interação entre o tratamento do substrato e as doses de nitrogênio exerceu efeitos significativos para massa seca da raiz e comprimento radicular, mostrando que existe interdependência entre esses fatores (TAB. 3).

Esses resultados evidenciam a adaptabilidade e rusticidade dessa espécie quanto ao tratamento de substrato, principalmente porque o substrato usado no experimento foi oriundo da região onde essa espécie é encontrada espontaneamente. 
Tabela 3 - Massa fresca de raiz (MFR), massa seca da raiz (MSR), volume radicular (VR), comprimento radicular (CR) de mudas de castanha-do-gurguéia em função de doses de $\mathrm{N}$ e aplicação de calcário e PK no substrato

\begin{tabular}{lcccc}
\hline \multirow{2}{*}{ Fonte de variação } & MFR & VR & MSR & CR \\
\cline { 2 - 5 } & - & & \\
\hline S (Trat. do solo) & $0,07^{\text {ns }}$ & $0,12^{\text {ns }}$ & $0,16^{\text {ns }}$ & $2,15^{\text {ns }}$ \\
S1 & $0,29 \mathrm{a}$ & $2,27 \mathrm{a}$ & $0,20 \mathrm{a}$ & $11,58 \mathrm{a}$ \\
S2 & $0,27 \mathrm{a}$ & $2,41 \mathrm{a}$ & $0,21 \mathrm{a}$ & $10,02 \mathrm{a}$ \\
DMS & 0,13 & 0,82 & 0,05 & 2,22 \\
N (Dose de N) & $7,56^{* *}$ & $7,96^{* *}$ & $51,33^{* *}$ & $51,20^{* *}$ \\
SXN & $2,41^{\text {ns }}$ & $0,81^{\text {ns }}$ & $13,47^{* *}$ & $3,29^{*}$ \\
\hline CV & 62,31 & 47,76 & 35,84 & 27,95 \\
\hline
\end{tabular}

DMS = diferença mínima significativa; $\mathrm{CV}$ = coeficiente de variação; $\mathrm{S} 1$ = substrato tratado; $\mathrm{S} 2$ = substrato não tratado; ${ }^{\mathrm{NS}}=$ não significativo; ${ }^{*}=$ significativo ao nível de $5 \% ;{ }^{* *}=$ significativo ao nível de $1 \%$; as médias seguidas pela mesma letra em cada coluna, não são diferentes estatisticamente pelo teste de Tukey a $1 \%$

Observou-se que houve efeito do $\mathrm{N}$ sobre a massa fresca de raiz (FIG. 7), no entanto a maior média foi obtida nas plantas em que não receberam adubação nitrogenada em cobertura $\left(0 \mathrm{mg} \mathrm{dm}^{-3}\right)$. Por outro lado, o volume radicular também foi influenciado pela adubação nitrogenada em cobertura, entretanto a maior média foi obtida com a aplicação de $75 \mathrm{mg} \mathrm{dm}^{-3}$ de N (FIG. 8). Nesse sentido, Bloom (1997) observou que o desenvolvimento radicular é resposta não apenas à quantidade de nitrogênio inorgânico da rizosfera, mas também à forma $\left(\mathrm{NH}_{3}^{+}, \mathrm{NH}_{4}^{+}\right.$ou $\left.\mathrm{NO}_{3}^{-}\right)$, o que

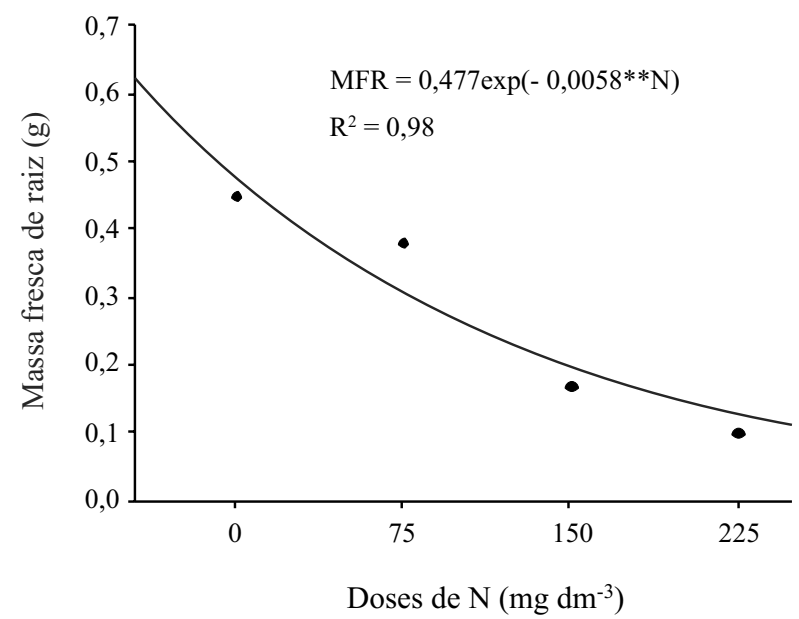

Figura 7 - Massa fresca de raiz (MFR) de mudas de castanhado-gurguéia em função de doses de $\mathrm{N}$ concorda com os resultados de Vamerali et al. (2009) ao concluírem que elevados níveis de adubação nitrogenada podem reduzir o crescimento radicular até um nível crítico, independentemente da disponibilidade hídrica, o que está em consonância e pode justificar os resultados do presente trabalho.

Comparando para massa seca da raiz (FIG. 9) o tratamento que não recebeu adubação nitrogenada em cobertura com o que recebeu a dose de $225 \mathrm{mg} \mathrm{dm}^{-3}$, houve um decréscimo de $93,1 \%$ no substrato tratado, e de $94,74 \%$ no substrato não tratado.

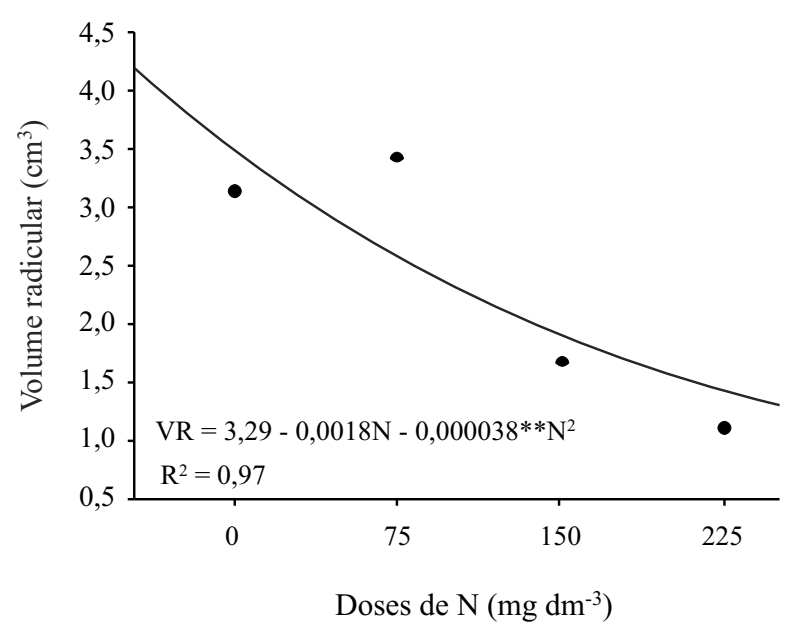

Figura 8 - Volume radícular (VR) de mudas de castanha-dogurguéia em função de doses de $\mathrm{N}$ 
O maior comprimento radicular (FIG. 10) encontrado no substrato tratado foi obtido nas mudas que receberam a aplicação de $75 \mathrm{mg} \mathrm{dm}^{-3}$ de $\mathrm{N}$ em cobertura, no entanto no substrato não tratado o maior comprimento radicular foi obtido nas mudas que não receberam adubação em cobertura.

É importante destacar que os processos de desenvolvimento do sistema radicular não são totalmente conhecidos ainda, em parte devido às diferentes respostas em função das espécies e, adicionalmente, os fatores externos que influenciam no desenvolvimento radicular incluindo nitrogênio inorgânico, $\mathrm{pH}$ e potencial redox que atuam simultaneamente (BLOOM et al., 2003).
Nesse sentido, Prado (2008) afirma que os principais aspectos de excesso de $\mathrm{N}$ absorvido e metabolizado estão relacionados ao desvio de carboidratos para as proteínas, o qual prejudica o desenvolvimento do sistema radicular, o que ficou evidenciado nas Figuras 7; 8; 9 e 10 com produção de mudas de castanha-do-gurguéia (Dipteryx lacunifera Ducke), visto que quanto maior a quantidade de $\mathrm{N}$ aplicada, menores foram as médias de crescimento e desenvolvimento radicular, inclusive de forma visual.

Benedetti et al. (2009) analisando a produção de mudas espinheira-santa (Maytenus ilicifolia), verificaram que, de maneira geral a omissão de $\mathrm{N}$ reduziu a relação MSPA/MSR. Segundo Taiz e Zeiger (2004), plantas em
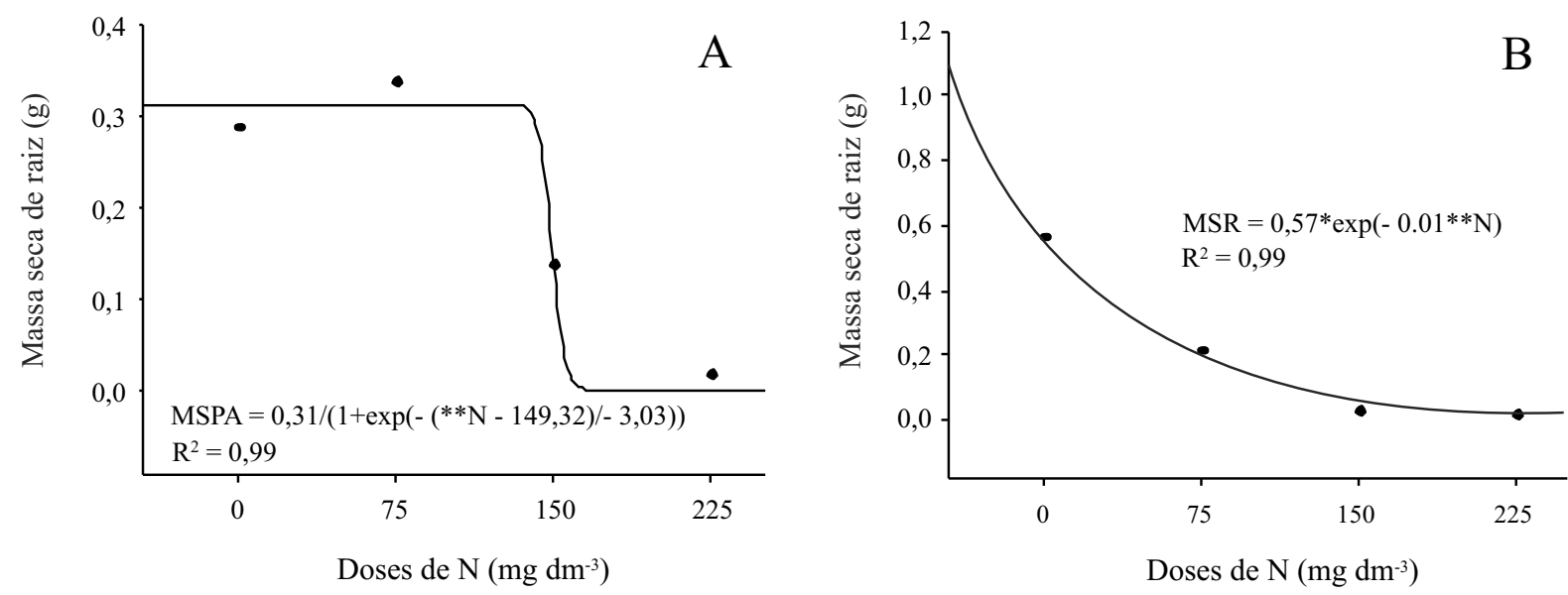

Figura 9 - Massa seca de raiz (MSR) de mudas de castanha-do-gurguéia em substrato com (A) e sem calcário e PK (B) e em função de doses de $\mathrm{N}$
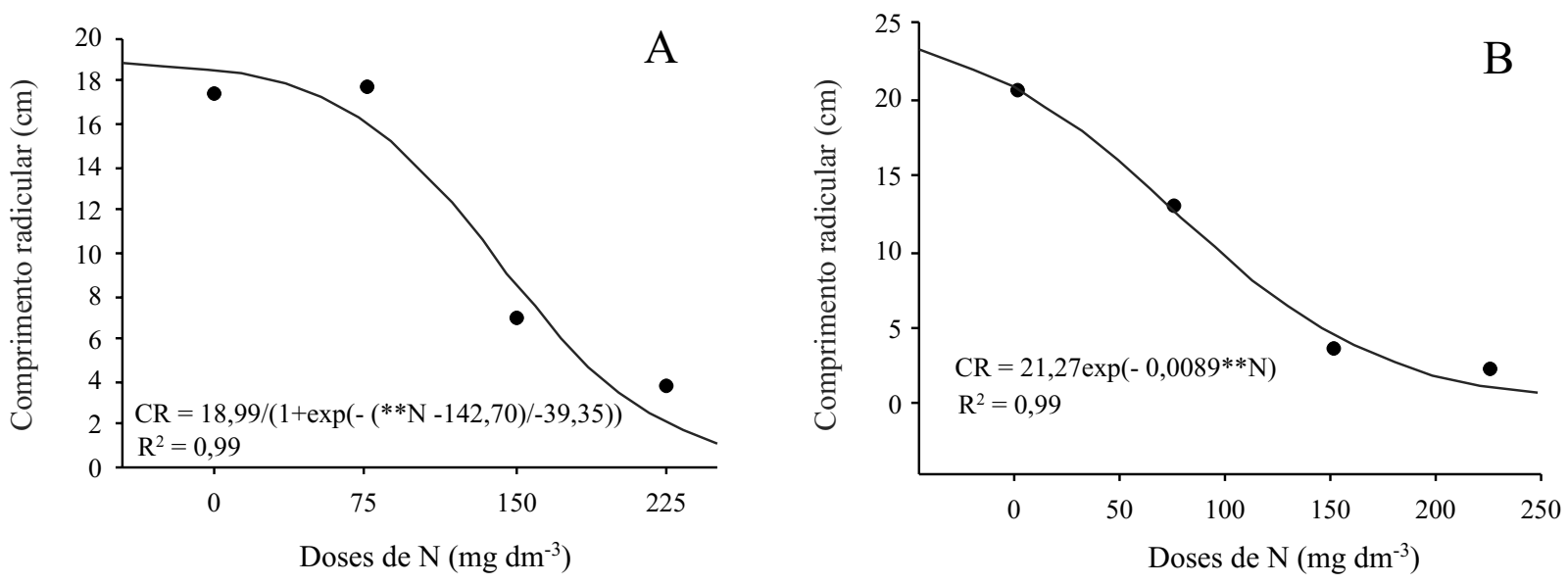

Figura 10 - Comprimento radicular (CR) de mudas de castanha-do-gurguéia em substrato tratado com (A) e sem calcário e PK (B) e em função de doses de $\mathrm{N}$ 
condições de deficiência nutricional tendem a investir mais energia na produção de raízes para ampliar o potencial de absorção desses nutrientes.

\section{Conclusões}

1. Há influência das doses de $\mathrm{N}$ na formação de mudas de castanha-do-gurguéia;

2. O substrato tratado (NEOSSOLO QUARTZARÊNICO) influencia positivamente o número de folíolos e a massa fresca da parte aérea;

3. Para a produção de mudas em substrato (NEOSSOLO QUARTZARÊNICO) sem calcário e $\mathrm{PK}$ não há necessidade de adubação nitrogenada em cobertura, enquanto para o substrato corrigido recomenda-se a dose de $75 \mathrm{mg} \mathrm{dm}^{-3} \mathrm{~N}$.

\section{Referências}

ARAÚJO, F. A. et al. Fixação biológica de N2 no feijoeiro submetido a dosagens de inoculante e tratamento químico na semente comparado à adubação nitrogenada. Acta Scientiarum: Agronomy, v. 29, n. 04, p. 535-540, 2007.

BASSO, S. M. S. Caracterização morfológica e fixação biológica de nitrogênio de espécies de Adesmia DC. E Lotus L. 1999. 268 f. Tese (Doutorado em Zootecnia) - Universidade Federal do Rio Grande do Sul, Porto Alegre, 1999.

BENEDETTI, E. L. et al. Crescimento e sintomas em mudas de espinheira-santa com omissão de nitrogênio, fósforo e potássio. Floresta, v. 39, n. 02, p. 335-343, 2009.

BLOOM, A. J. Interactions between inorganic nitrogen nutrition and root development. Z Pflanzenerna hr Bodenk, v. 160, p. 253-259. 1997.

BLOOM, A. J. et al. Root Development and Absorption of Ammonium and Nitrate from the Rhizosphere. Journal of Plant Growth Regulation, v. 21, n. 04, p. 416-431, 2003.

CARVALHO, M. G. et al. Avaliação dos parâmetros físicos e nutricionais de amêndoas de chichá, sapucaia e castanha-do-gurguéia. Revista Ciência Agronômica, v. 39, n. 04, p. 517-523, 2008.

CHAVES, L. B. et al. Efeitos da inoculação com rizóbio e da adubação nitrogenada na produção de mudas de Sesbânia em substrato constituído de resíduos agroindustriais. Revista Árvore, v. 27, n. 04, p. 443-449, 2003.
CRUZ, C. A. F. et al. Efeito da adubação nitrogenada na produção de mudas de sete-cascas (Samanea inopinata (Harms) Ducke). Revista Árvore, v. 30, n. 04, p. 537-546, 2006.

FERNANDES, L. A. et al. Níveis de nitrogênio, fósforo e potássio para a produção de mudas de fava d'anta (Dimorphandra mollis Benth). Revista Brasileira de Plantas Medicinais, v. 10, n. 01, p. 94-99, 2008.

GERENDAS, J. et al. Significance of nickel for plant growth and metabolism. Journal of Plant Nutrition and Soil Science, v. 162, n. 03, p. 241-256, 1999.

GOMES, J. M. et al. Parâmetros morfolágicos na avaliação da qualidade de mudas de Eucalyptus grandis. Revista Árvore, v. 26, n. 06, p. 655-664, 2002.

HARTMANN, H. T. et al. Plant Propagation: principles and practices. 7. ed. New Jersey: Prentice Hall, 2002. 880 p.

MALAVOLTA, E. Elementos de nutrição mineral de plantas. São Paulo: Ceres, 1980. 251 p.

MARQUES, V. B. et al. Efeitos de fontes e doses de nitrogênio no crescimento de mudas de sabiá (Mimosa caesalpiniaefolia Benth.). Scientia Forestalis, n. 71, p. 77-85, 2006 a.

MARQUES, V. B. et al. Efeito de fontes e doses de nitrogênio sobre o crescimento inicial e qualidade de mudas de jacarandáda-bahia (Dalbergia nigra (Vell.) Fr. All. ex Benth.). Revista Árvore, v. 30, n. 05, p. 725-735, $2006 \mathrm{~b}$.

MARSCHNER, H. Mineral nutrition of higher plants. London: Academic Press,2005. 889 p.

PRADO, R. M. Nutrição de plantas. São Paulo: UNESP, 2008.

ROCHA, L. F. Fava-de-morcego e araçá do cerrado: dormência de sementes e substrato para mudas. In: SEMINÁRIO DE INICIAÇÃO CIENTÍFICA DA UFPI, 18., 2009, Teresina. Anais... Teresina: UFPI, 2009. CD-ROM.

SANTIN, D. et al. Crescimento de mudas de erva-mate fertilizadas com N, P e K. Scientia Agraria, v. 09, n. 01, p. 59-66, 2008.

TAIZ, L.; ZEIGER, E. Fisiologia vegetal. 3. ed. Porto Alegre: Artmed, 2004. 719 p.

VAMERALI, T. et al. Effects of water and nitrogen management on fibrous root distribution and turnover in sugar beet. European Journal of Agronomy, v. 31, n. 02, p. 69-76, 2009.

VIEIRA JUNIOR, G. M. et al. Terpenos e ácidos graxos de Dipteryx lacunifera Ducke. Química Nova, v. 30, n. 07, p. 1658-1662, 2007. 